\title{
Editorial: Institutional Experimentation for Better (or Worse) Work
}

Work is currently being turned upside down, with major changes affecting how people experience their work, participate in their communities and live their lives. Existing institutions seem out of synch with the experience of so many. In the most developed economies of the West, so many of the institutions that have sought to foster solidarity, equality and prosperity throughout the $20^{\text {th }}$ century, seem unable to respond to today's workers needs and aspirations. There is an aspiration for productive, innovative, healthy and inclusive work, in which individuals live free from excessive insecurity and threats to their health and well-being, expect to exercise some degree of control and autonomy in their working lives, and achieve economic democracy and citizenship in a sustainable and solidaristic vision of prosperity for all citizens and future generations - what we label better work. Better work speaks to both the conditions of the work experience and the employment status and labour rights that come with it. However, quite a different picture emerges from a neoliberal era, in which fragmented supply chains, financialisation, climate change, new digital technologies and global health pandemics (Covid-19) result in worse work and disjointed communities.

Yet, this disconnect with the objectives and effects of institutions that regulate work and employment also opens up space for actor resilience and experimentation. At many levels, in different national, institutional and organisational contexts, and in conditions of uncertainty, various forms of worker organizations, old and new, are experimenting in response to the major fault lines of change they face. This special issue focuses on these processes: the disruption of traditional forms of regulation of work and employment; how a variety of actors are engaged in experimentation about the governance of work and employment; how these actors are making claims on the state; how these processes can lead to better and to worse work; and how strong sets of capabilities and particular configurations of resources on the part of those engaged in experimentation can contribute to new forms of work regulation and indeed better work. The stakes are high since these experiments are likely to shape our economies and communities of the future. A key challenge will be to aggregate understanding of these processes and to engage in shared learning. This special issue aims to contribute to this objective.

The five articles in this issue represent preliminary results from an international and interdisciplinary collaborative research project: the CRIMT International Partnership Project on Institutional Experimentation for Better Work. Funded by the Social Sciences and Humanities Research Council of Canada, this multi-year project (date) brings together a wide variety of Partner Centres and other affiliated researchers in more than a dozen countries in an ongoing dialogue on the theoretical and practical challenges of experimentation in the regulation of work and employment. The articles draw on just a few such cases with a view to sparking researchers to bring other cases into this dialogue and comparative discussion. The aim is also to stimulate a wide range of actors in the world of work to take up the lens of experimentation in the way that they strategize, innovate and embrace uncertainty in their practical search for enduring institutional solutions for better work.

What is this experimentation and why is it taking place? The disruption in the regulation inherited from the Fordist era has pushed collective actors in the world of work to seek new responses to continue to nurture solidarity, equality and shared prosperity. As explored in the particular contributions in this special issue, this has led worker organizations and labour-friendly actors to experiment on behalf of, and with, their members or the working 
people affected by various forms of insecurity. Faced with disruption and uncertainty, they feel compelled to develop new solutions, to recombine traditional aspects of the regulation of work and employment in novel ways. Such examples of experimentation are a response to, and often nested within, the neoliberal experimentation that preceded it, indeed dealing with the worse work that resulted from these ongoing neoliberal experiments.

Murray, Lévesque, Morgan and Roby seek to frame our understanding of these processes. In what they label hybrid experimentation, they set out how a variety of actors experiment with new ways of organising and seek to institutionalise them into new understandings, norms and rules in the regulation of work and employment. They explore efforts to move outside customary repertoires, and to recombine old and new sources in two types of experimentation: first, organisational experimentation, where actors seek to modify or renew their organisations, networks and alliances and reflect on, assess and learn from their experiments; second, institutional experimentation, where these responses are scaled up and institutionalised over time through more general understandings, norms and rules. The authors illustrate these processes and the challenges to sustainability and scaling up such experiments face through the examples of coworking and non-traditional forms of union representation.

Charles, Ferreras and Lamine examine ongoing experimentation in the case of SMart, a worker cooperative in Belgium where freelancers (originally with no access to union or employment coverage), have tried to promote and institutionalise access to a larger set of social rights for such workers. This initiative has attracted much attention because it represents a possible democratic institutional response to a major issue in contemporary labour markets, namely the proliferation of precarious work. The authors illustrate how SMart has sought to reorient the access to the benefits of Belgian social security system on behalf workers who previously worked beyond the reach of such State protections. Moreover, SMart provides its members with a collective capability to face the many sources of uncertainty affecting them, thus potentially offering a measure of stability in their incomes, and nurturing their quest for expressivity and autonomy in the government of their own work.

Pulignano, Thompson and Doerflinger analyse paired cases of experimentation and counter-experimentation in the global logistics industry where, enabled by digital technologies, new business models experiment with institutional constraints and increasingly bad forms of work to gain competitive advantage and drive productivity and profitability, albeit at the cost of heightened work intensity and diminished control over work processes. The cases they analyse provide a good illustration of what Murray, Lévesque, Morgan and Roby label neoliberal experimentation, as exemplified by the worse work and superexploitation of the so-called "self-employed" in parcel delivery. However, the resulting disruption and uncertainty also spark counter-experimentation as the objects of these experiments become its subjects. Through their unions, they seek to be political agents of their own transformation, engaged in hybrid experiments to recombine resources and repertoires and to mobilize in unconventional ways the institutional resources available to them.

For Bosch and Schmidt, the genesis of "Arbeit 2020" was to move beyond the uncontrolled decentralisation visited on German unions by their employers seeking to exert exit options from wider German collective bargaining coverage in the 1990s. This neoliberal experimentation led to concessions on wages and working time on the basis of threats to subcontract to companies beyond the scope of collective agreements within and outside of Germany - strategies that in fact did little to improve productive processes. The objective for 
IG Metall and its partner unions was to shift from a defensive position to one of agency. The focus was on how to empower the largely untapped institutional resource of works councillors so that these actors might play a more proactive role in shaping of the transformation of their workplaces. Arbeit 2020 was devised by unions involved, with the benefit of state financial resources, as a field experiment around the implementation of Industry 4.0 technologies and processes. The diversity of situations and their underlying social dynamics made it impossible to start with fixed specifications about how exactly change should be shaped. Rather, the development of worker expertise and experimentalism in the search for practical solutions in the engagement with the firms where they worked were the guiding principles.

The case presented by Heather Connolly represents a perfect storm for union representation in local government in the United Kingdom. The local authority in question was itself a poster child for neoliberal experimentation in public sector management, championing downsizing, privatisation and outsourcing with a stated objective of achieving zero salaried employment - a literal caricature of a neoliberal nirvana which has seen gone into receivership. The proclaimed objective was to outsource all jobs. Faced with this existential threat, the major union organisation in this local authority had to re-think its strategies in response to the dire challenges it faced. This was all the more important because its defensive role as a "co-designer" of previous iterations of public sector austerity had literally drained the life from its local union branch. Facing this radical marketisation project prompted a strategic rethink, with a focus on democratic experimentalism to rekindle union life.

A number of key characteristics run through these cases of experimentation.

First, experimentation for better or worse work is about agency - the resilience of those who are experimenting, their identities and their resources leading to collective capabilities. This entails changing and recombining repertoires of action, combining out-ofthe box actions with traditional structures and policies, in order to test real-time responses to uncertainty through action. This can draw on traditional legacies, but often combines in novel ways power resources and regulatory legacies. For Bosch and Schmidt, IG Metall and its partner unions aimed to develop through Arbeit 2020 a new combination between its external expertise (their staff and the consultants hired with the support of public funds) and newly enabled works councillors and local managers within work places to engage in proactive modernization strategies. For Pulignano, Thompson and Doerflinger, the unions drew on traditional regulatory legacies in new ways, at the interstices between organisational and institutional experimentation, to protect working conditions. For Connolly, in response to one of the more egregious manifestations of neoliberal experimentation, a local union branch sees few other options than to experiment on itself. The renewal of its collective identity requires greater deliberative capacity to renew its repertoire of actions. A key point, illustrated by the SMart case, is how such experimentation can generate a range of new collective capabilities. Rather than seeing co-working as just more collateral damage from the neoliberal fissuring of the workplace, Murray, Lévesque, Morgan and Roby argue that it also presents the seeds of hybrid experimentation, opening up the possibility of new forms of solidarity and collective capability. So too for their example of UE Local 150 which, drawing on the repertoires and identity of a range of social and religious movements rooted in the black community in North Carolina, redefines itself in a creative strategy to organise workers in hostile environments like those of the southern states in the US. 
Second, deliberation, participation and democracy are critical for experimentation. For Charles, Ferreras and Lamine, SMart highlights the importance of the direct involvement of workers because experimentalism draws on that first-hand knowledge to nourish collective problem solving. SMart is an example of democratic experimentation because it is continuously redefined and redesigned by its members, individually weak yet collectively capable. In so doing, it has the potential to erode neoliberalism from within by upholding the traditional objectives and values of the labour movement, equality, solidarity, democratic participation and government. For Bosch and Schmidt, the aim to develop local union competencies on work processes and industrial policy was premised on deliberation and the untapped potential of workforce participation. However, experiments do falter through uneven participation and opposition to the disruptive nature of experiments, as was the case for some works councillors and union partners in Arbeit 2020. In the UK union branch explored by Connolly, full-time officials from above and activists from below engaged in a process of democratic experimentalism that challenged the existing 'insider' relationship between branch officers and management. For Murray, Lévesque, Morgan and Roby, experimentation in co-working represents a hybrid potential for new forms of solidarity between atomized workers, but can just as easily legitimise a model of fissured and displaced work in the absence of participation and deliberative capacity.

Third, experimentation is both strategic and reflexive. Although some experimentation is emergent, as in the case of the UE Local 150 and the co-working dynamics explored by Murray, Lévesque, Morgan and Roby, experimentation is most often the result of a continuous process of strategising and learning from doing. That other unions and communities are learning from these examples and are now experimenting with their own versions highlights this dynamic. Bosch and Schmitz illustrate how union strategy has driven the Arbeit 2020 experimentation and how reflexivity and learning are central to this ongoing process. Likewise, the case presented by Connolly starts from the need to rethink how the local union branch operates in the face of radical disruption. For Pulignano, Thompson and Doerflinger, experimentation required the trade unions to be reflexive in order to identify the causes of bad working conditions and to use their resources to improve these conditions in a novel way. SMart's continuous effort to strategise has prompted emulation and learning across borders in Europe as a potential institutional response to precariousness.

Fourth, a key issue for organisational experimentation, as identified by Murray, Lévesque, Morgan and Roby, is its sustainability and scalability. In other words, to what extent can hybrid organisational experiments be sustained and upscaled through various forms or stages of institutionalisation. None of the cases of experimentation presented here represent an easy or universally accepted option. Indeed, this speaks to the very tentative nature of experimental processes. SMart, as an attempt to build a worker cooperative crowded by freelancers turned wage earners, has attracted attention because it represents an effort to identify a collective solution to one of the key problems of neoliberal experimentation, namely the outsourcing of work out of the firm and the impact on the employment structure and those who do this work. The transition of Arbeit 2020 into a larger union reform project by IG Metall points to an ambition to institutionalise this transformation, illustrating a potential movement from organisational to institutional experimentation. However, as illustrated by several of the cases, this is by no means a given, as experimentation is typically uneven and may present little opportunity for upscaling. This depends in particular on the response of State actors, on the possibility to build larger political coalitions and alliances, and on the ability to mobilize and make claims on public policy in efforts to upscale experimentation. Yet, and this is the power of experimentation, it presents that potential. 
Carried out at the right moment, cases of experimentation can institutionalise the values of equality, solidarity, shared prosperity and democracy. Although we do not necessarily know from where the next advances in the regulation of work and employment will occur, they are most likely to spring from attempts by actors to deal with the uncertainties they face. This is also likely to highlight the need to deliberate over and define an agenda, to learn from it and in so doing, to develop capabilities and repertoires of action in novel ways. As researchers, we are convinced that major social advances, like collective bargaining and social security, have been made possible not because the right theoretical framework was in place, but because collective actors in the world of work innovated in order to find solutions to the real-life problems they faced. They have sought structured ways to address the uncertainty workers faced, which is the core premise of the experimentation explored by all the authors in this special issue. These collective actors then worked to upscale and extend these solutions, organisationally and institutionally, through deliberation, shared learning and emulation, by enhancing their resources and developing their capabilities, and by constructing larger political movements for transformative change.

Finally, such an approach has important implications for the ways that researchers engage in their research. As can be seen in the contributions to this special issue, most of the articles draw on some direct or indirect involvement in experimentation processes. There is a systematic need for comparative research to understand the conditions of experimentation: the constraining and facilitating conditions, the strategic blending, the role of resources and deliberation, the lessons to be drawn from these experiences and the bridges between organisational and institutional experimentation. Such a research agenda entails two requirements: first, the need for new models of aggregation and cross-interrogation, so that examples of experimentation can speak to each other; second, an ongoing dialogue between actors and researchers in and about processes of experimentation. A key question for the research community, as suggested by experimentalism, is how it engages in nurturing the democratic nature of society by helping actors reflect critically and constructively upon their own actions and by helping empower the public to become capable to solve its own problems.

We hope that this thematic issue offers a modest, first step in this direction. In particular, we wish to thank the Transfer co-editors and managing editor, Philippe Pochet, Jeremy Waddington and Marina Luttrell, for their deft and insightful editorial work as well as the useful and timely comments from all of the editors and referees in helping to improve all the articles and steer this issue to fruition. We also wish to acknowledge the insightful contributions of our many colleagues in the CRIMT Partnership Project on Institutional Experimentation for Better Work to our ongoing collective thinking about experimentation and its potential as a transformative lens for the world of work.

Isabelle Ferreras, Ian MacDonald, Gregor Murray and Valeria Pulignano

Version submitted - 23-3-2020 